\title{
Visual Analysis on Knowledge Management Research Using Citespace
}

\author{
Jincheng Shi ${ }^{1}$, Ru Zhang ${ }^{2,3}$, Hongfei Guo ${ }^{2,4}$, Yi Zhou ${ }^{2,5}$, Changxing Deng ${ }^{2,4}$, Fan Yang ${ }^{2,4}$, Yalei Feng ${ }^{2,4}$ \& \\ Naibiao $\operatorname{Jin}^{2,4}$ \\ ${ }^{1}$ Office of Scientific R\&D, Jinan University, Guangzhou, China \\ ${ }^{2}$ Institute of Physical Internet, Jinan University, Zhuhai, China \\ ${ }^{3}$ Institute of management science and engineering, Jinan University, Zhuhai, China \\ ${ }^{4}$ School of Intelligent Systems Science and Engineering, Jinan University, Zhuhai, China \\ ${ }^{5}$ School of Electrical Engineering, Jinan University, Zhuhai, China \\ Correspondence: Hongfei Guo, Institute of Physical Internet, Jinan University, Zhuhai, 519070, China. E-mail: \\ ghf-2005@163.com
}

Received: May 30, 2019

Accepted: June 20, 2019 Online Published: August 29, 2019

doi:10.5539/jms.v9n2p83

URL: https://doi.org/10.5539/jms.v9n2p83

\begin{abstract}
In recent years, research on knowledge management has become a hot issue in academia and industry. From the research literature of existing scholars on knowledge management, although research in this field has yielded a large amount of important research results, however, there is a lack of quantitative literature review to summarize the current status and development of the field. Most studies lack in-depth and extensional research on the basis of predecessors. This paper uses the bibliometric method to conduct statistical analysis of the literature in the field of knowledge management research, perform visualized analysis of the content of knowledge management research with citespace software, aiming to further understand the development of knowledge management research through analysis of relevant literature, frontier hotspots and future trends. The results of the research show: knowledge management research enters explosive development stage; Interdisciplinary and multidisciplinary research will gradually become the direction of development in this field; the integration of knowledge management and big data will become future research trend.
\end{abstract}

Keywords: knowledge management, bibliometric method, visualized analysis

\section{Introduction}

Knowledge management is defined as the integration, development and storage of organizational knowledge (Tekic \& Willoughby, 2019). On the one hand, knowledge management can effectively prevent or slow down the loss and depreciation of organizational knowledge by integrating organizational data, information and knowledge. On the other hand, it also supports the decision-making of organizational strategy (Choi, Kim, \& Yun, 2019; Kim, Springer, Zhang, \& Park, 2019); knowledge management is the specific support for the organization's knowledge management implementation. The existing research directions of knowledge management can be divided into knowledge management process, knowledge management strategy, knowledge classification, knowledge measurement, related research has been very rich. However, there is a lack of quantitative review analysis to summarize the current status and development of the field, most studies lack in-depth and extensional research on the basis of predecessors. Therefore, this paper adopts the relevant theories and methods of bibliometric analysis, utilizes the visualized tool Citespace software. Conduct statistical and visual analysis of the knowledge management field, aiming to provide a summary and guidance for theory and application.

\section{Method and Data Collection}

\subsection{Methodology}

Combining the content analysis and mapping knowledge domains analysis to perform metrological analysis in the field of knowledge management research. Content analysis refers to the identification of research topics through recognition of feature keyword and extraction, word frequency statistics and analysis to identify research 
topics. Mapping knowledge domains analysis refers to analyzing the research hotspot, evolution trend and knowledge base of knowledge management research through three kinds of maps: co-word network, distribution time series and co-citation network.

\subsection{Data Collection}

The subject of this research is related literature in the field of knowledge management. The data source is Web of Science (WOS) database. To enable the data collection of this study to comprehensively cover the research status in this field, subject heading search are selected, the time span is defined as 2000 to 2018. Key word is "knowledge management", a total of 19,391 related documents of the WOS database were finalized.

\section{Statistics and Visualized Analysis}

\subsection{Research Hotspot Analysis}

In content analysis method, key words which are sight words can be used to characterize the relevant literature and identify research hotspots in the field of knowledge management research (Abraham, Feathers, Grieve, \& Babichenko, 2019; Aung, Luan, \& Xu, 2019; Badiu, Onose, Nita, \& Lafortezza, 2019; Bagheri, Kusters, Trienekens, \& Grefen, 2019). The higher the frequency of the keyword, the more the research content represented by the keyword is concerned, namely research hotspot. According to the literature data collected by WOS data, mapping knowledge of research hotspots in the field of knowledge management is drawn, as shown in Figure 1.

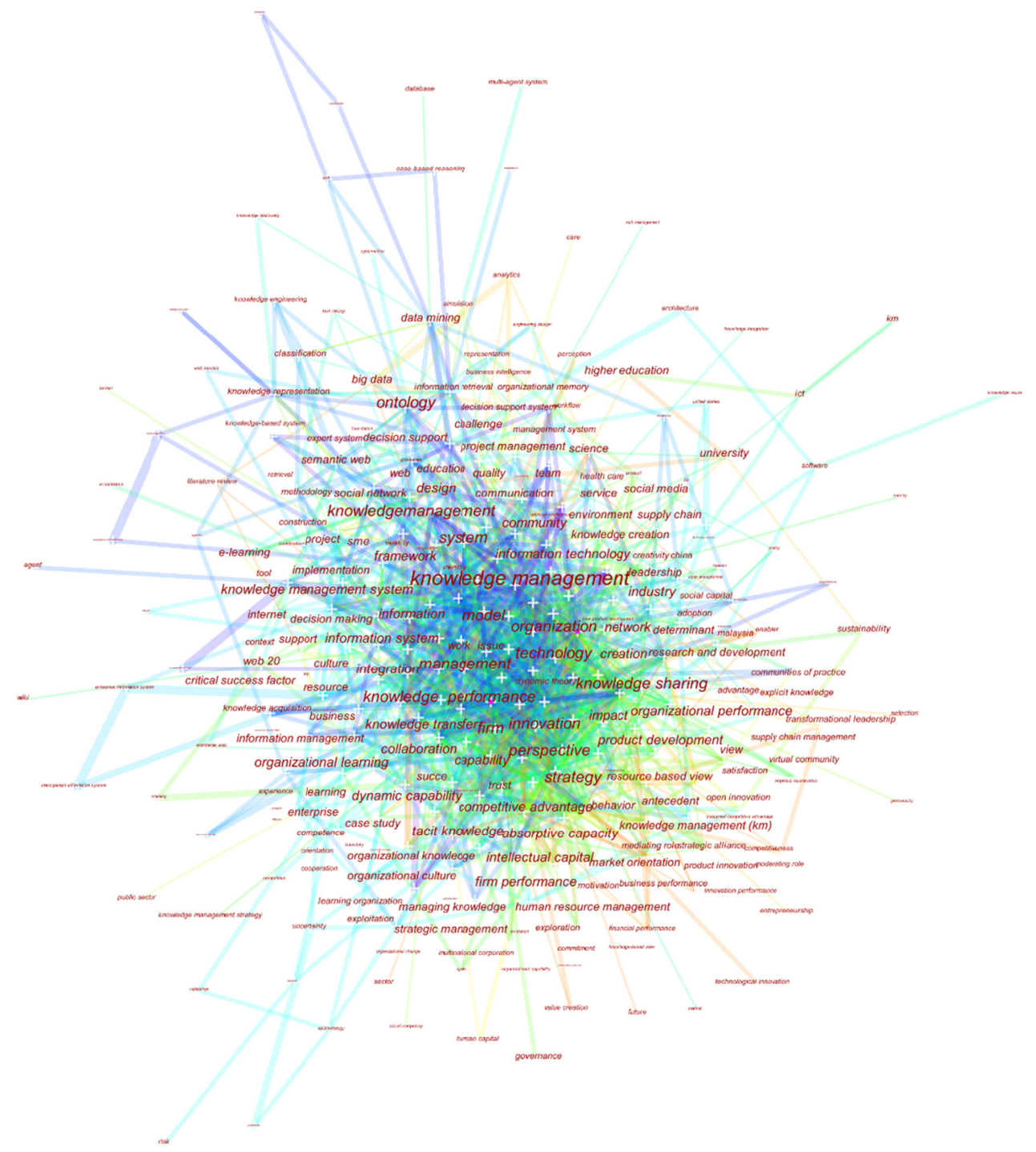

Figure 1. Knowledge mapping of research hotspots 
Combine synonyms, filter non-real words, and summarize order of occurrence of keywords based on the frequency in Table 1.

Table 1. Statistics of research hotspot in knowledge management

\begin{tabular}{llll}
\hline Order & Keywords & Frequency & Centrality \\
\hline 1 & knowledge management & 9059 & 0.1 \\
2 & performance & 1735 & 0.12 \\
3 & innovation & 1691 & 0.07 \\
4 & management & 1584 & 0.05 \\
5 & system & 1449 & 0.03 \\
6 & firm & 1190 & 0.06 \\
7 & model & 1158 & 0.04 \\
8 & knowledge & 1011 & 0.01 \\
9 & perspective & 985 & 0.07 \\
10 & organization & 818 & 0.04 \\
\hline
\end{tabular}

It can be seen from the analysis of Figure 1 and Table 1, in this knowledge mapping-co-word network: co-word network centers on "knowledge management", research hotspot words like "performance", "innovation", "management" and so on are closely around the network center, the size of the font corresponds to the size of its node degree. On the whole, the frequency distribution of keywords in the field of knowledge management has little difference, however, the network center degree of different commonly used words has a large gap, which means The attention received by different research hotspots is relatively close, there are great differences in academic status and serving as a link between past and future of subjects. Meanwhile, the overall density of the common word network is high, indicating that the research direction in the field of knowledge management is more concentrated, and the development of the subject is introverted. Specifically, the above analysis found that the research hotspots of knowledge management from 2000 to 2018 can be summarized as the following aspects:

1) Enterprise management, including knowledge management of organization, performance, and management

2) Innovation. Effective knowledge management is an effective way for organizations to achieve innovation.

3) Modeling. Knowledge management has evolved from a general strategic plan to a more generalized, conceptualized, and mathematical model that can more effectively implement the cross-individual, cross-organizational, cross-domain migration, evolution, and application of knowledge management policies.

\subsection{Evolution Trend Analysis}

The evolution trend refers to the research hotspots and the distribution of research topics in the field of subject in different years. Using the knowledge mapping of the sequence diagram, you can get the evolution trend in the field of knowledge management (Abraham et al., 2019; Aung et al., 2019; Badiu et al., 2019; Bagheri et al., 2019). According to the literature data collected from WOS data, knowledge mapping that draw the evolution of knowledge management, as shown in Figure 2.

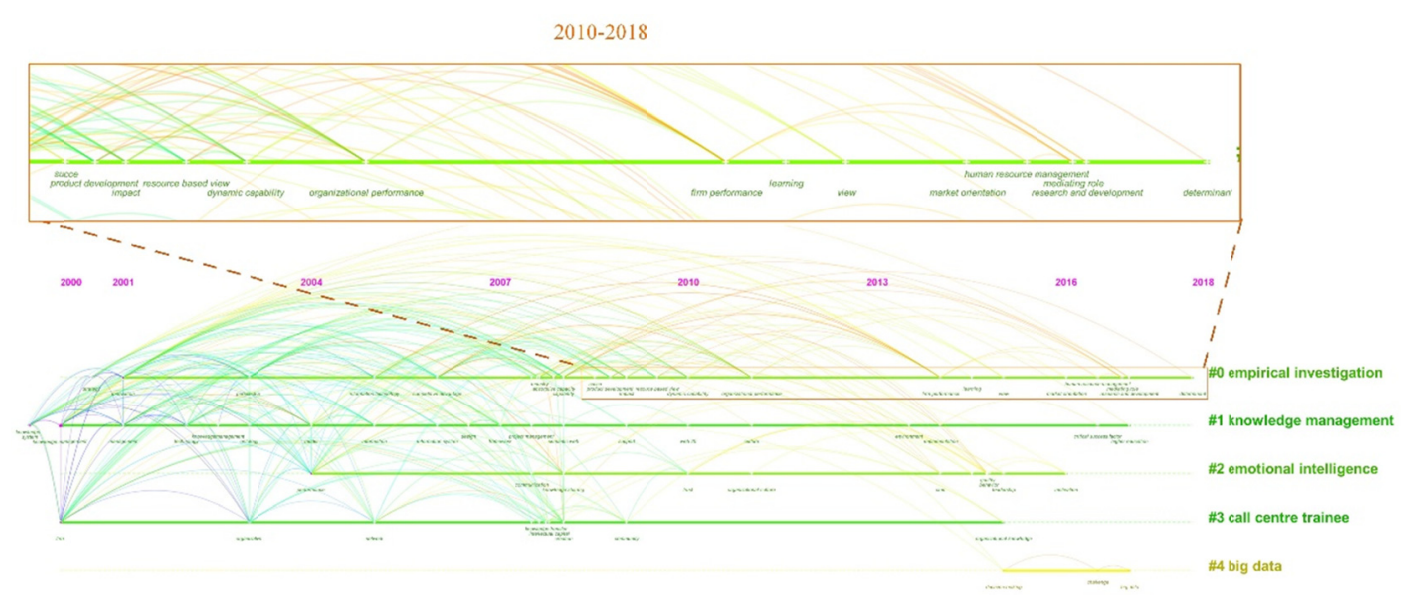

Figure 2. Knowledge mapping of research hotspots 
Through academic research and industry practice test, the research evolution trend in the field of knowledge management presents multi-disciplinary intersections, both theory and application, deepening and parallelization. Analysis of the evolutionary trend of knowledge management research between 2000 and 2018 in the world can lead to the following conclusions:

From 2000 to 2007, the keywords were: "information systom", “information technology", "model”, etc. This shows that knowledge management research is still in the germination period of academic theory and the technical accumulation period in industrial applications. In academic research, knowledge management, as an organizational model of management, is used to analyze and enhance the relative competitive advantage of enterprises, and can be promoted to a strategy; at the same time, the implementation of knowledge management is inseparable from the support of information management technology, the former Instigated the rise of the latter.

From 2008 to 2010, the keywords were: "knowledge sharing", "industry absorptive capacity", "web 2.0", etc. This shows that knowledge management derives the concept of knowledge sharing, which is inseparable from the support of basic communication technology and the network era. Iteration; at the same time, knowledge management also enhances the industrial absorptive capacity, that is, the ability of knowledge sharing, absorption, re-creation, and application among industrial entities.

From 2010 to 2018, the key words are "human resource management", "firm performance", "environment", etc., which means that knowledge management has moved from the industrial production line to the enterprise management level, from human resource management, performance management, the impact of business based on the environment, and so on.

\subsection{Knowledge Base Analysis}

The knowledge base refers to the citations and common trajectory in the research front of the subject areas. Using the common network knowledge map, the author firstly identifies and screens the authoritative and classic literature works in the field of knowledge management, and then analyzes the evolution process of the field through content analysis, and clarifies the important nodes of the discipline development (Abraham et al., 2019; Aung et al., 2019; Badiu et al., 2019; Bagheri et al., 2019). According to the data from the literature collected by WOS data, mapping knowledge domains of the knowledge base in the knowledge management field is drawn, as shown in Figure 3.

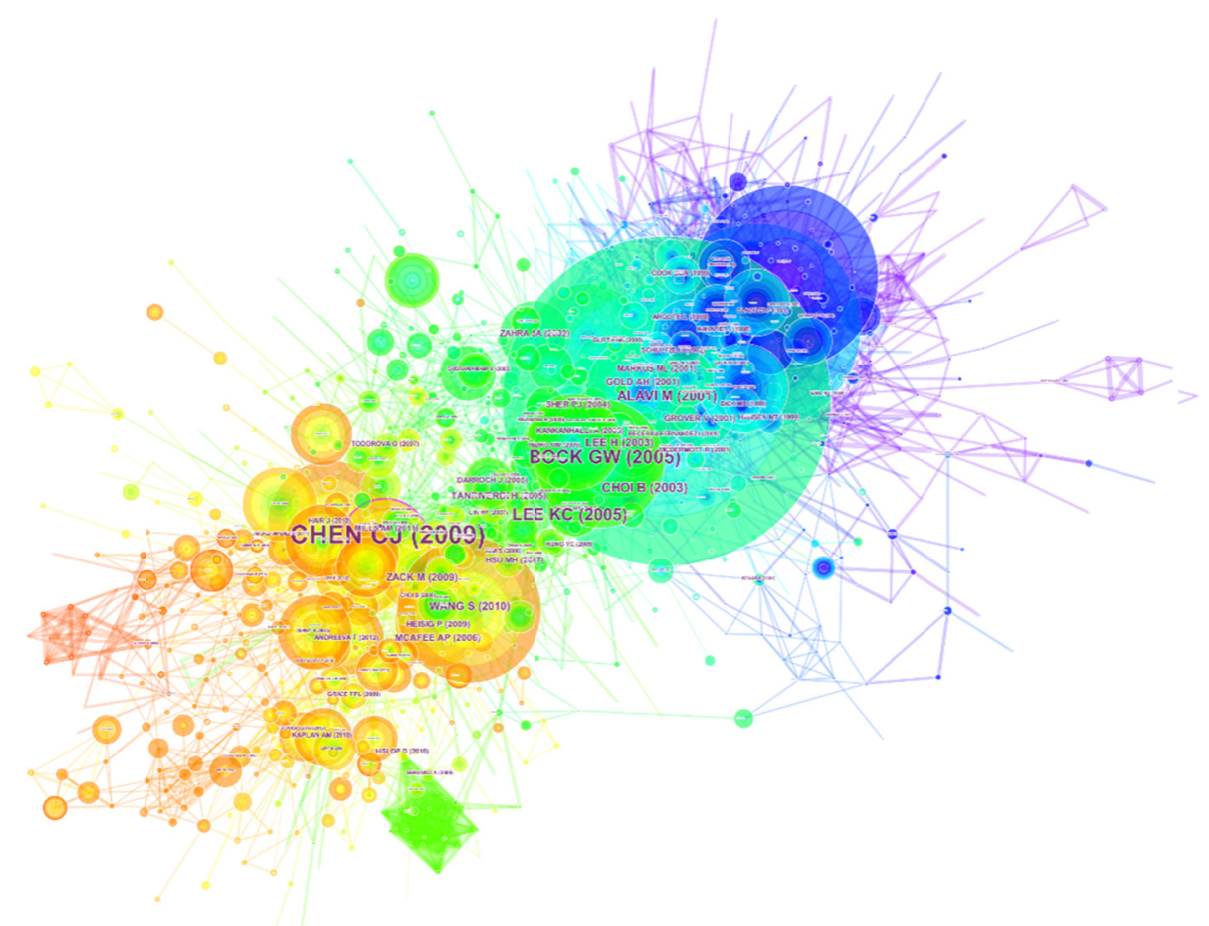

Figure 3. Knowledge mapping of research citation

The order of the document center degree is summarized in Table 2. 
Table 2. Classic literature in the field of knowledge management

\begin{tabular}{|c|c|c|c|}
\hline Order & Title & Year & Cited \\
\hline 1 & $\begin{array}{l}\text { Strategic human resource practices and innovation - The mediating role of knowledge } \\
\text { management capacity }\end{array}$ & 2009 & 1129 \\
\hline 2 & $\begin{array}{l}\text { Behavioral Intention Formation in Knowledge Sharing: Examining the Roles of Extrinsic } \\
\text { Motivators, Social-Psychological Forces, and Organizational Climate }\end{array}$ & 2005 & 4262 \\
\hline 3 & KMPI: Measuring knowledge management performance & 2005 & 686 \\
\hline 4 & $\begin{array}{l}\text { An Empirical Investigation of Knowledge Management Styles and Their Effect on Corporate } \\
\text { Performance }\end{array}$ & 2003 & 909 \\
\hline 5 & $\begin{array}{l}\text { Knowledge management and knowledge management systems: Conceptual foundations and } \\
\text { research issues }\end{array}$ & 2001 & 11996 \\
\hline 6 & Knowledge sharing: A review and directions for future research & 2010 & 2020 \\
\hline 7 & Enterprise 2.0: The dawn of emergent collaboration & 2006 & 2144 \\
\hline 8 & $\begin{array}{l}\text { Information technology relatedness, knowledge management capability, and performance of } \\
\text { multibusiness firms }\end{array}$ & 2005 & 890 \\
\hline 9 & Knowledge Management and Organizational Performance: An Exploratory Survey & 2009 & 691 \\
\hline 10 & $\begin{array}{l}\text { Knowledge management enablers, processes, and organizational performance: An integrative } \\
\text { view and empirical examination }\end{array}$ & 2003 & 2402 \\
\hline
\end{tabular}

Through visual analysis of mapping knowledge domains-interpenetrating networks, e ten most influential documents in the field of knowledge management are get. This series of classical literatures has instructive significance on the theoretical basis and application practice of the research field, laying the framework for the research paradigm of the whole field. Chen and Huang (2009) investigated the role of knowledge management capabilities in the relationship between strategic human resource practices and innovation performance. Finally, they found that strategic human resource practices are positively related to knowledge management capabilities, which in turn have a positive impact on innovation performance; knowledge management capabilities play a mediating role between strategic human resource practices and innovation performance. Bock, Zmud, Kim, and Lee (2005) used the rational action theory (TRA) as the theoretical framework and used external motivation, social psychological strength and organizational climate factors to enhance the theory. They confirmed our hypothesis that attitudes and subjective norms of knowledge sharing and organizational climate influence individuals' intention to share knowledge. In addition, they found that expected reciprocal relationships affect individual attitudes toward knowledge sharing, while self-worth and organizational climate all influence subjective norms. Contrary to popular belief, the expected external rewards have a negative impact on an individual's knowledge-sharing attitude. Lee, Lee, and Kang (2005) provided a new metric, the Knowledge Management Performance Index (KMPI), which is used to assess a company's knowledge management (KM) performance at a point in time. They linked KMPI to three financial indicators: stock price, price-earnings ratio (PER) and R\&D spending. The statistical results show that the proposed KMPI can represent Resent KCP efficiency, and three financial performance indicators are also useful. Choi and Lee (2003) analyzed how various KM styles affect performance. It turns out that KM methods can be divided into four types: dynamic, systematic, human and passive. The focus of dynamic style is on people-oriented and system-oriented styles with higher performance. More high-performance humanized and systematic style. People-oriented and system-oriented styles do not differ in company performance; passive style results are consistent with previous observations that implicit and explicit knowledge are important in leveraging company knowledge. Alavi and Leidner (2001) reviewed and explained the knowledge management literature in different fields, focusing on identifying important research areas. They present a detailed process of organizing knowledge management views that focus on the potential role of information technology in this process. Drawing on literature review and knowledge management process analysis, they discussed several important research issues surrounding knowledge management-age processes and the role of IT in supporting these processes. Wang and Noe (2010) reviewed the qualitative and quantitative research of knowledge sharing at the individual level. Based on the literature review, they developed a framework for understanding knowledge sharing research. The framework identifies five key areas of knowledge sharing: organizational context, interpersonal and team characteristics, cultural characteristics, personal characteristics, and motivational factors. Tanriverdi (2005) proposed that knowledge management (KM) is the key organizational capability of IT to influence company performance. In the context of a multi-business company, the study examined how to organize and manage a company's IT resources to improve the company's knowledge management capabilities, and whether and how knowledge management 
capabilities affect company performance. The study proposes two hypotheses: (1) IT relevance of the company's business unit enhances cross-sector knowledge management capabilities; (2) In turn, knowledge management capabilities can lead to superior business performance. Data from 250 Fortune 1000 companies provide empirical support for these assumptions. The IT relevance of the business unit enhances the company's cross-functional knowledge management capabilities. Knowledge management capabilities create and leverage cross-cell synergies from the company's products, customers and management knowledge resources. These synergies increase the company's financial performance. Through the mediation of KM capabilities, IT correlation also has a significant indirect impact on company performance. McKeen, Zack, and Singh (2006)'s research on $\mathrm{KG}$ results is related to the exploratory investigation of the organizational impact of knowledge management (KM). The search literature reveals $12 \mathrm{KM}$ practices. The results show that these knowledge management is directly related to organizational performance, and organizational performance is directly related to organizational performance. In addition, a different set of knowledge management is associated with a specific value discipline (i.e., customer intimacy, product development and operational excellence). Interestingly, there is a significant gap between knowledge management, legally considered important, and intellectuals directly related to organizational performance. The significance of this research is important to both practitioners and scholars. Advised on future work in this area. Lee and Choi (2003) developed a research model that links knowledge management factors to each other. The model includes seven drivers: collaboration, trust, learning, centralization, formalization, T-shaped skills and information technology support. The focus is on the process of knowledge creation, such as socialization, externalization, combination and internalization of information technology support that only have a positive impact on the knowledge portfolio. Discovering organizational creativity is critical to improving performance; neglecting ideas can undermine business. The results can serve as a stepping stone to further empirical research and can help develop powerful strategies that involve trade-offs between knowledge management facilitators.

\section{Conclusion}

Through using the method of documentary metrology and the visualized tool Citespace software, we conducted quantitative analysis on the related literatures in the field of knowledge management from three aspects: research hotspots, evolution trends, and knowledge bases. The collection of knowledge mappings in this field are outlined and summarized, provides more theoretical and practical guidance for academia and industry.

\section{Acknowledgments}

The research and publication of their article was supported by the Fundamental Research Funds for the Central Universities (No. 21618804 and No. 21618412); the Teaching Reform Research Project of Jinan University in 2019 (No. JC2019181 and No. JC2019168); the National Natural Science Foundation of China (No. 51475095).

\section{Reference}

Abraham, O., Feathers, A., Grieve, L., \& Babichenko, D. (2019). Developing and piloting a serious game to educate children about over-the-counter medication safety. Journal of Pharmaceutical Health Services Research, 10(2), 235-241. https://doi.org/10.1111/jphs.12292

Alavi, M., \& Leidner, D. E. (2001). Knowledge management and knowledge management systems: Conceptual foundations and research issues. MIS Quarterly, 25(1), 107-136. https://doi.org/10.2307/3250961

Aung, T. S., Luan, S. J., \& Xu, Q. Y. (2019). Application of multi-criteria-decision approach for the analysis of medical waste management systems in Myanmar. Journal of Cleaner Production, 222, 733-745. https://doi.org/10.1016/j.jclepro.2019.03.049

Badiu, D. L., Onose, D. A., Nita, M. R., \& Lafortezza, R. (2019). From "red" to green? A look into the evolution of green spaces in a post-socialist city. Landscape and Urban Planning, 187, 156-164. https://doi.org/10.1016/j.landurbplan.2018.07.015

Bagheri, S., Kusters, R. J., Trienekens, J. J. M., \& Grefen, P. W. P. J. (2019). A reference model-based user requirements elicitation process: Toward operational business-IT alignment in a co-creation value network. Information and Software Technology, 111, 72-85. https://doi.org/10.1016/j.infsof.2019.03.012

Bock, G.-W., Zmud, R. W., Kim, Y.-G., \& Lee, J.-N. (2005). Behavioral intention formation in knowledge sharing: Examining the roles of extrinsic motivators, social-psychological factors, and organizational climate. MIS Quarterly, 29(1), 87-111. https://doi.org/10.2307/25148669

Chen, C.-J., \& Huang, J.-W. (2009). Strategic human resource practices and innovation performance-The mediating role of knowledge management capacity. Journal of Business Research, 62(1), 104-114. 
https://doi.org/10.1016/j.jbusres.2007.11.016

Choi, B., \& Lee, H. (2003). An empirical investigation of KM styles and their effect on corporate performance. Information \& Management, 40(5), 403-417. https://doi.org/10.1016/S0378-7206(02)00060-5

Choi, W., Kim, S. L., \& Yun, S. (2019). A Social Exchange Perspective of Abusive Supervision and Knowledge Sharing: Investigating the Moderating Effects of Psychological Contract Fulfillment and Self-Enhancement Motive. Journal of Business and Psychology, 34(3), 305-319. https://doi.org/10.1007/s10869-018-9542-0

Kim, I., Springer, M., Zhang, Z. G., \& Park, Y. S. (2019). Organizational learning: Approximation of multiple-level learning and forgetting by an aggregated single-level model. Computers \& Industrial Engineering, 131, 442-454. https://doi.org/10.1016/j.cie.2018.10.004

Lee, H., \& Choi, B. (2003). Knowledge management enablers, processes, and organizational performance: an integrative view and empirical examination. Journal of Management Information Systems, 20(1), 179-228. https://doi.org/10.1080/07421222.2003.11045756

Lee, K. C., Lee, S., \& Kang, I. W. (2005). KMPI: measuring knowledge management performance. Information \& Management, 42(3), 469-482. https://doi.org/10.1016/j.im.2004.02.003

McKeen, J. D., Zack, M. H., \& Singh, S. (2006). Knowledge management and organizational performance: an exploratory survey. IEEE. https://doi.org/10.1109/HICSS.2006.242

Tanriverdi, H. (2005). Information technology relatedness, knowledge management capability, and performance of multibusiness firms. MIS Quarterly, 29(2), 311-334. https://doi.org/10.2307/25148681

Tekic, A., \& Willoughby, K. (2019). Co-creation — child, sibling or adopted cousin of open innovation? Innovation-Organization \& Management, 21(2), 274-297. https://doi.org/10.1080/14479338.2018.1530565

Wang, S., \& Noe, R. A. (2010). Knowledge sharing: A review and directions for future research. Human Resource Management Review, 20(2), 115-131. https://doi.org/10.1016/j.hrmr.2009.10.001

\section{Copyrights}

Copyright for this article is retained by the author, with first publication rights granted to the journal.

This is an open-access article distributed under the terms and conditions of the Creative Commons Attribution license (http://creativecommons.org/licenses/by/4.0/). 